\title{
CORRESPONDENCE
}

\section{EARLY OPERATION FOR SQUINT}

\section{To the Editorial Committee of the British JouRnal of OPHTHALMOLOGY}

SIRS,-It is the common experience of those surgeons who operate early on children with constant convergent squint of onset before the age of 2 years that, in those cases which they are able to follow up, if all the manifest obstacles to development of binocular vision are removed, a small proportion will attain full binocularity, a much larger proportion will become partially binocular (constant slight deviation, usually with abnormal retinal correspondence, fusion with some amplitude, and some degree of stereoscopic vision), and the remainder will either develop no fusion amplitude or continue to suppress the image of one or other eye.

Dr. Arruga and Miss Downey (Arruga and Downey, 1960) condemn the practice of early operation because of the apparent impossibility of improving on the condition of partial binocular vision, and recommend constant occlusion until operation at a later age on the ground that abnormal retinal correspondence can thus be prevented. But they offer no evidence that the development of fusion (which cannot under these conditions have begun) will then proceed. If they can show that by prolonged occlusion and later operation better binocular results are attained in these constant convergent squints of early onset than by straightening the eyes as soon as this can be done, apart from the practical difficulty and possibly adverse psychological results of continuous occlusion for several years, earlier operation might well be contraindicated. There cannot be much scope for orthoptics unless fusion begins, even at this late stage, to develop spontaneously, and if this does not happen in a reasonable proportion of these cases (of constant convergence with early onset), some surgeons would prefer to obtain fusion amplitude with abnormal retinal correspondence than to maintain normal retinal correspondence but with little or no fusion.

\section{Yours faithfully,}

\section{G. J. O. Bridgeman.}

6, Devonshire Place,

W.1.

January 7, 1961.

\section{REFERENCE}

Arruga, A., and Downey, R. (1960). Brit. J. Ophthal., 44, 492.

\section{BOOK REVIEWS}

The Ophthalmologist (Der Augenarzt). Volume III. Edited by K. Velhagen. 1960. Pp. 1194, 814 figs (345 col.). Thieme, Leipzig. (D.M. 194.50.)

The third volume of this admirable series, which has now been published, should receive as wide a welcome as its predecessors. Diseases of the eyelids are discussed by Heydenreich (Magdeburg), of the conjunctiva by Rieger (Linz), of the cornea by Günther (Greifswald), of the lens by Sautter (Hamburg), and of the vitreous by Hruby (Graz), and anomalies of the aqueous humour by Remky (Munich). A long section by Hamburger 